\title{
Study of Protective Effects of Gold Nano Particles on the Liver Toxicity Induced by Carbon-Tetrachloride $\left(\mathrm{CCl}_{4}\right)$ in Male Rats
}

\author{
Mohammad Reza Shahraki, ${ }^{1,}$ Hamideh Mirshekari, ${ }^{2}$ Fereshteh Badini, ${ }^{3}$ Mohammad Reza Arab, ${ }^{4}$ and
}

\author{
Elham Shahraki ${ }^{5}$ \\ ${ }^{1}$ Department of Physiology, Faculty of Medicine, Zahedan University of Medical Sciences, Zahedan, Iran \\ ${ }^{2}$ Specalist of Infectious Disease, Zahedan Health Center, Zahedan University of Medical Sciences, Zahedan, Iran \\ ${ }^{3}$ MSc of Animal Physiology, Department of Biology, Faculty of Science Payam-e-Noor University, Tehran, Iran \\ ${ }^{4}$ Department of Histology, Faculty of Medicine, Zahedan University of Medical Sciences, Zahedan, Iran \\ ${ }^{5}$ Department of internal Medicine, Faculty of Medicine, Zahedan University of Medical Sciences, Zahedan, Iran \\ "Corresponding author: Mohammad Reza Shahraki, Professor of Physiology, Department of Physiology, Faculty of Medicine, Zahedan University of Medical Sciences and \\ Health Services, Zahedan, Iran. Tel: +98-5413414552-5, Fax: +98-5413414563, E-mail: m_shahrakim@zaums.ac.ir
}

Received 2016 October 08; Revised 2017 June 10; Accepted 2017 July 23.

\begin{abstract}
Background: Since gold nanoparticle (AuNP) has shown anti-oxidant activity, this study was designed to assess the effect of AuNP on the liver toxicity induced by Carbon -Tetrachloride $\left(\mathrm{CCl}_{4}\right)$ in rats.

Methods: A total of 36 Wistar-albino male rats, weighing 200 - 250 g, were randomly split into three groups (control, $\mathrm{CCl}_{4}$ and CCl${ }_{4}+$ AuNP; $\mathrm{n}=12)$ after 5 days of accommodation. Groups $\mathrm{CCl}_{4}$ and $\mathrm{CCl}_{4}+$ AuNP as experimental were injected with $\mathrm{CCl}_{4}(1 \mathrm{mlL} / \mathrm{kg} \mathrm{b.w})$ for a period of 42 days intraperitonealy (ip), while control (c) group received saline intraperitonealy. On the seventh week of the study, group $\mathrm{CCl}_{4}+$ AuNP received additional AuNP and saline suspension for a period of three days. Finally, blood samples were collected from their cervical vessels. Liver enzymes activity, superoxide dismutase (SOD), catalase and malondialdeide (MDA) were measured in serum. Prepared sections of liver specimens were stained with $\mathrm{H}$ and $\mathrm{E}$ and PAS methods for histological studies. The data was analyzed by SPSS v. 17; applying one -way ANOVA, Tukey as well as nonparametric tests.

Results: Results showed that aspartate aminotransferase (AST), alanine aminotransferase (ALT) and Alkaline phosphatase (ALP) in groups $\mathrm{CCl}_{4}$ and $\mathrm{CCl}_{4}+$ AuNP significantly increased compared to group control, but MDA and SOD values decreased compared to

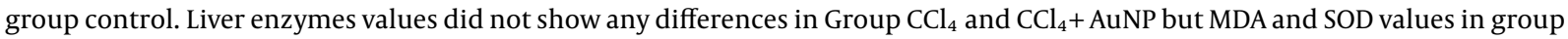
$\mathrm{CCl}_{4}+$ AuNP decreased and increased respectively in comparison to group $\mathrm{CCl}_{4}$. Histological evaluation showed fatty metamorphosis and micro nodular cirrhotic changes in $\mathrm{CCl}_{4}$ group but gold nanoparticles did not show a remarkable protective effect.

Conclusions: AuNP administration affected MDA and SOD in hepatotoxicity induced by $\mathrm{CCl}_{4}$ in male rats but did not improve liver enzymes damage.
\end{abstract}

Keywords: Hepatotoxicity, AST, ALT, ALP, Rat, Fatty Metamorphosis

\section{Background}

Liver damage is accompanied by modern eating habits, many environmental contaminants, and exaggerating consumption of syntheticmedicines. $\mathrm{CCl}_{4}$ is a chemical toxin which causes liver toxicity [1]. In addition, liver cells and microsomes display the central role for different drug metabolism and excretions [2]. The critical effect of Carbon Tetrachloride is morphological alterations in liver cells [3]. Exposure to hepatotoxic compounds may affect the tumor necrosis factor-alpha (TNF alpha) expression in many acute and chronic liver diseases, and promote the damages of hepatocytes [4]. The classic toxicity of $\mathrm{CCl}_{4}$ speeds up liver injury and liver fibrosis. Liver fibrosis is a result of chronic liver injury, which can progress into liver cirrhosis [5]. Since AuNps have hydrophilic and hydrophobic nature, they easily inter cells and alter the cell function but their effects depend commonly on the size of this nanoparticle $[6,7]$.

In addition, the volume of the NPs plays an important role in diffusion process of particles in the attachment process [8]. Gold nanoparticles are actually used as drug distribution mediator [9] and are actually used in food improving industry, and diagnosis and treatment of cancer (10). In addition, Siddiqi NJ (2014) reported that administration of gold nanoparticles in rats causes increased superoxide dismutase (SOD) and antioxidant enzymes activity in liver [10]. Connor E.E. et al. (2005) found that gold nanoparticle administration in human did not show any toxicity despite being taken up into cells [11]. Moreover, the experiment revealed that gold nanoparticle injection into rats from tail vein distributed in various organs such as brain, lung, liver, heart, kidney, blood, testis and thymus but did not show any toxicity [12]. Gold nanoparticles are usually 
used in food packaging, drinks, toothpaste, cars, and lubricants [13]. Umair M, et al. (2016) considered that nanoparticles of gold are observed as biologically inert [14]. Nanoparticles (NPs) have specific properties which make them suitable for imaging, therapy, and drug delivery [15]. According to the above mentioned report [14] and since gold nanoparticle of AuNP has shown anti-oxidant activity, this trail was designed to assess the antioxidant effect of AuNP on the liver toxicity induced by carbon -tetrachloride $\left(\mathrm{CCl}_{4}\right)$ in male rats.

\section{Methods}

A total of 36 Wistar-albino male rats, weighing 200 - $250 \mathrm{~g}$, were randomly split into three groups (control, $\mathrm{CCl}_{4}$ and $\mathrm{CCl}_{4}+$ AuNP; $\mathrm{n}=12$ ) after 5 days of accommodation. Groups 2 and 3 as experimental were injected with $\mathrm{CCl}_{4}$ liquefied in fluid paraffin ( $1 \mathrm{~mL} / \mathrm{kg}$ b.w) for a period of 42 days intraperitonealy (ip), while control group (c) received saline intraperitonealy and also fluid paraffin (1 $\mathrm{mL} / \mathrm{kg}$ body weight) subcutaneously every other day in trial period $[16,17]$. On the seventh week of the study, group 3 received additional colloidal suspensions of $20 \mathrm{~nm}$ gold nanoparticles (AuNP) intraperitonealy, repeatedly administered in saline solution at dose levels of $90 \mu \mathrm{g}$ for three days [18]. All animals had free access to water and food during the trial period and were sustained in a room at $23 \pm$ $2{ }^{\circ} \mathrm{C}$ temperature of fixed 12: 12-hours synthetic light/dark period ( 6 am to $6 \mathrm{pm}$ ), with humidity of $45 \%-65 \%$. Hepatotoxicity in groups $\mathrm{CCl}_{4}$ and $\mathrm{CCl}_{4}+$ AuNP were induced by subcutaneous injection of $\mathrm{CCl}_{4}$ liquefied in fluid paraffin (30\% solution), in a dosage of $1 \mathrm{~mL} / \mathrm{kg}$ body weight, for 6 weeks.

Finally, after overnight fasting (12 - 13 hours), the animals were anesthetized with diethyl ether and decapitated; immediately afterwards, blood samples were collected from cervical vessels. At first, a section of blood samples was collected in $\mathrm{CBC}$ (complete blood count) tub which were coated by EDTA for SOD measurements. Serum was separated from remaining blood samples and stored at $-70^{\circ} \mathrm{C}$ for further analyses. Activity of serum liver enzymes of ALT, AST, Lactate dehydrogenase (LDH), and ALP was measured blind applying standard methods using Pars Azmon kit Iran. Finally, the animal's liver was dissected out, immediately washed with tap water, and fixed in formalin saline10\%. Afterwards, according to routine methods in pathological Lab. $6 \mu$ sections were prepared and stained with $\mathrm{H}$ and $\mathrm{E}$ and PAS methods.

These animal experiments were all carried out in accordance with recommendations from the declaration of Helsinki and internationally conventional standards for the utilization of experimental animals, and received ethical authorization from the committee for animal research of Zahedan University of Medical Sciences (project No7355).

Data were collected in specific table and their normal distribution was permitted by Kolmogorov-Smirnov test, and was analyzed by SPSS v. 17; applying one -way ANOVA, Tukey as well as nonparametric tests. Obtained results were shown as mean $\pm S D$. Statistical alterations were painstakingly considered significant at $\mathrm{P}<0.05$.

\section{Results}

The obtained results indicated that liver enzymes activity of ALT, AST and ALP in groups $\mathrm{CCl}_{4}$ and $\mathrm{CCl}_{4}+\mathrm{AuNP}$, which received $\mathrm{CCl}_{4}$, significantly increased compared to control group; however, no significant differences were observed between groups $\mathrm{CCl}_{4}$ and $\mathrm{CCl}_{4}+\mathrm{AuNP}$ (Table 1). Lactate dehydrogenase ( $\mathrm{LDH}$ ) value significantly increased in group $\mathrm{CCl}_{4}+$ AuNP compared to group $\mathrm{CCl}_{4}$ but did not show any significant alterations in comparison to control group (Table 1 and Figure 1). In addition, malondialdeide (MDA) in groups $\mathrm{CCl}_{4}+$ AuNP and $\mathrm{CCl}_{4}$ significantly decreased compared to control group; however, between the two experimental groups $\left(\mathrm{CCl}_{4}+\mathrm{AuNP}\right.$ and $\left.\mathrm{CCl}_{4}\right)$ significant differences were not observed (Table 1, Figure 2). Moreover, superoxide dismutase (SOD) value in group $\mathrm{CCl}_{4}+$ AuNP significantly increased compared to group $\mathrm{CCl}_{4}$ but did not show any significant differences compared to control group (Table 1, Figure 3).

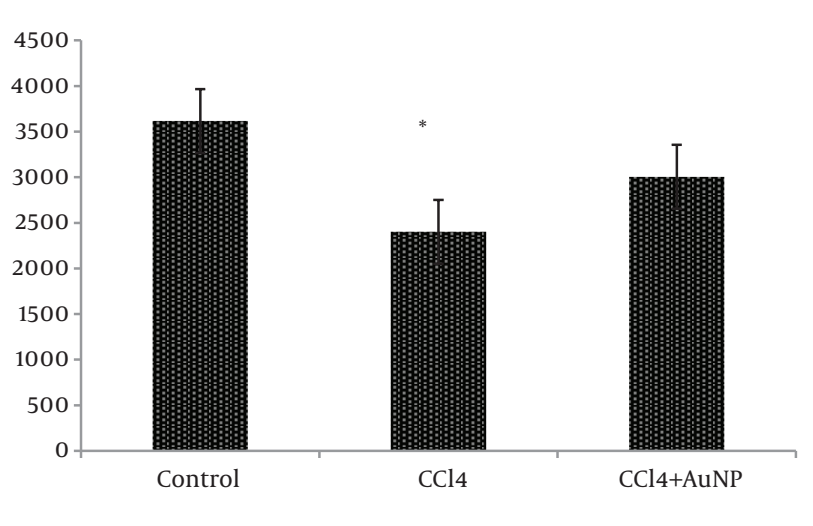

Figure 1. $\mathrm{LDH}$ Value (iu/L, Mean $\pm \mathrm{SD}$ ) in Control, $\mathrm{CCL}_{4}$ and $\mathrm{CCL}_{4}+\mathrm{AuNP}$ Groups. $\mathrm{n}=$ $12,{ }^{*}=\mathrm{P}<0.05$

Histological studies showed fatty metamorphosis and micro nodular cirrhotic changes in the experimental groups which received $\mathrm{CCl}_{4}$ injection; furthermore, there were prominent gross pathological changes in liver surface, including loss of smooth appearance of hepatic capsule. Findings revealed that nanoparticles had no promi- 
Table 1. The Effect of AuNP on $\mathrm{CCl}_{4}$-Treated Induced Alterations in Serum Hepatic Enzymes Including AST, ALT, ALP, LDH, MDA and SOD in Male Rats ${ }^{\mathrm{a}}$

\begin{tabular}{|c|c|c|c|c|}
\hline \multirow[t]{2}{*}{ Parameters } & \multicolumn{3}{|c|}{ Groups } & \multirow[t]{2}{*}{ P Value } \\
\hline & Control & $\mathrm{CCl}_{4}$ & $\mathrm{CCl}_{4}+\mathrm{AuNP}$ & \\
\hline $\operatorname{ALT}(\mathbf{i u} / \mathbf{L})$ & $62.83 \pm 6.04$ & $566.72 \pm 279.95^{\mathrm{b}}$ & $634.41 \pm 316.12^{\mathrm{b}}$ & 0.001 \\
\hline $\operatorname{AST}(\mathbf{i u} / \mathbf{L})$ & $233.25 \pm 32.75$ & $1650.81 \pm 696.79^{b}$ & $1530.08 \pm 414.11^{\mathrm{b}}$ & 0.001 \\
\hline $\operatorname{ALP}(\mathbf{i u} / \mathbf{L})$ & $488.91 \pm 234.76$ & $1469.00 \pm 358.51^{\mathrm{b}}$ & $1714.58 \pm 554.72^{\mathrm{b}}$ & 0.001 \\
\hline
\end{tabular}

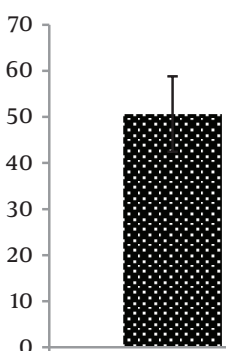

Control

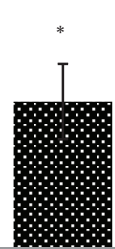

$\mathrm{CCl} 4$

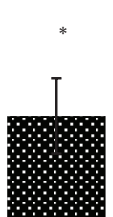

CCl4+AuNP

Figure 2. MDA Value $(\mu \mathrm{M} / \mathrm{L} \pm \mathrm{SD})$ in Control, $\mathrm{CCL}_{4}$ and $\mathrm{CCl}_{4}+\mathrm{AuNP}_{\text {Groups. } \mathrm{n}=12 \text {, }}$ $=\mathrm{P}<0.05$

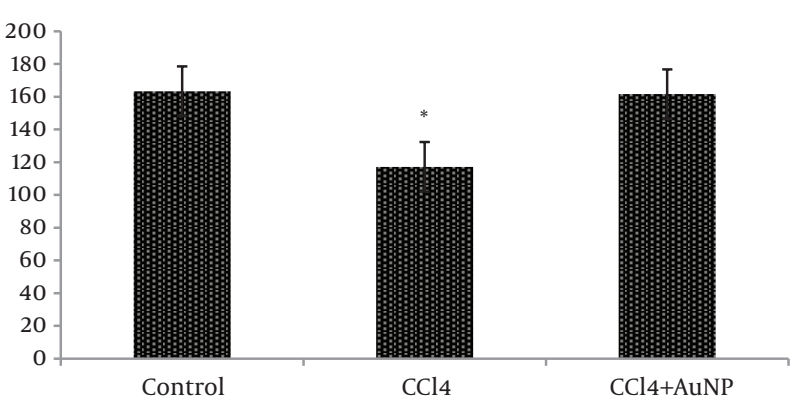

Figure 3. SOD Values (iu/L Mean $\pm \mathrm{SD}$ ) in Control, $\mathrm{CCL}_{4}$ and $\mathrm{CCL}_{4}+\mathrm{AuNP}$ Groups .n $=$ $12,{ }^{*}=\mathrm{P}<0.05$

nent protective on hepatocyte in the experimental groups. It seems that $\mathrm{CCl}_{4}$ induces so many pathological changes in liver parenchyma and vascular elements including sinusoids (micrograph 1 - 5).

\section{Discussion}

Liver injury is always correlated with cellular necrosis, which increases lipid peroxidation (LP), and reduces malondialdehyde (MDA) and glutathione (GSH) content linked with elevated liver enzymes [19]. Carbon tetrachloride $\left(\mathrm{CCl}_{4}\right)$ is a xenobiotic which is the leading cause

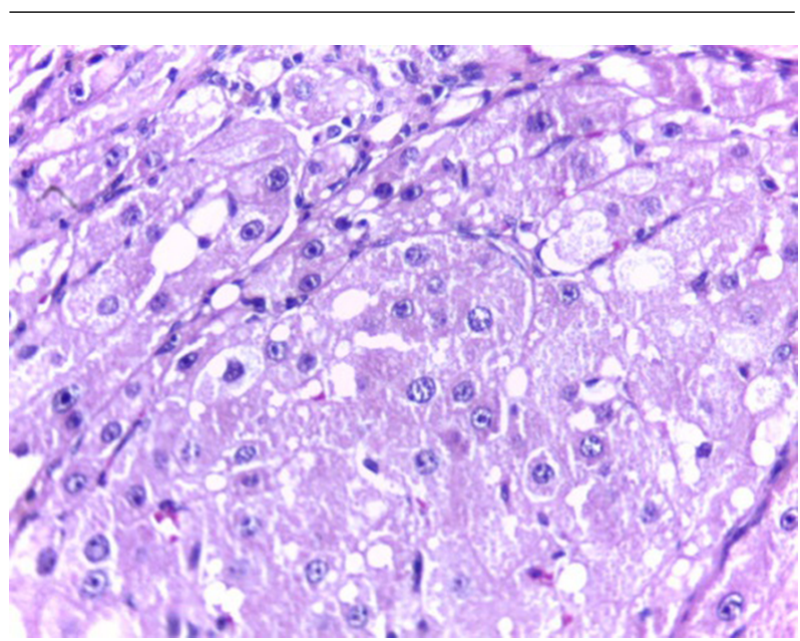

Figure 4. Micrograph of an $\mathrm{H}$ and E Stained Section of $\mathrm{CCL}_{4}$ Experimental Group Showing Fatty Metamorphosis, $\times 40$

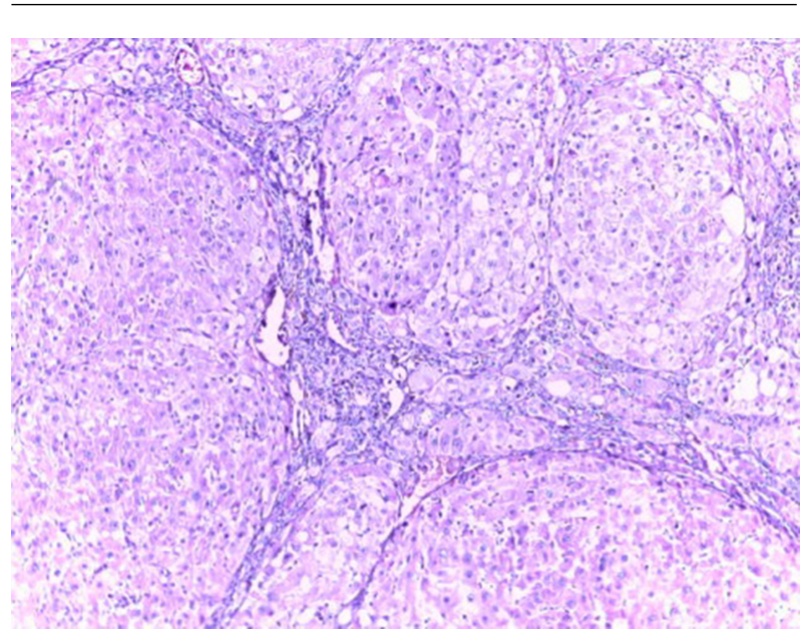

Figure 5. Micrograph of an $\mathrm{H}$ and $\mathrm{E}$ Stained Section of $\mathrm{CCL}_{4}$ Experimental Group Showing Micro Nodular Cirrhotic Changes, $\times 40$

of severe liver damage throughout its bio activation to 


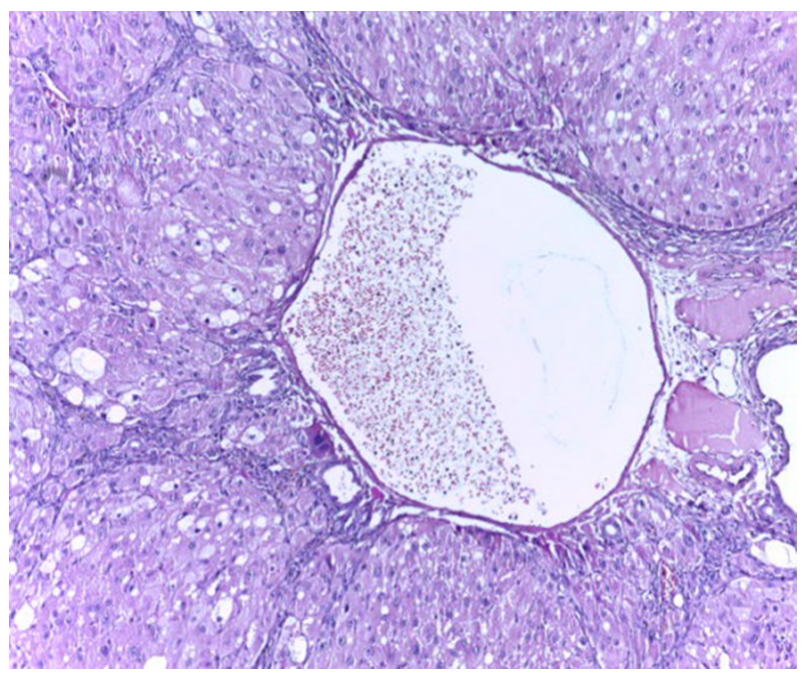

Figure 6. Micrograph of an $\mathrm{H}$ and E Stained Section of $\mathrm{CCL}_{4}$ Experimental Group Showing Vascular Dilation, $\times 40$

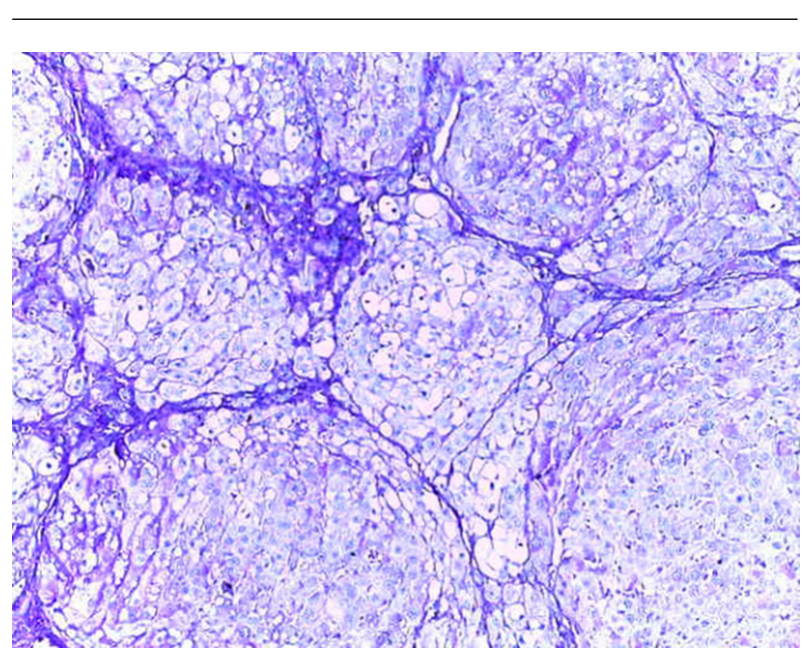

Figure 7. Micrograph of a PAS Stained Section of $\mathrm{CCL}_{4}$ Experimental Group Prominent Reduction of Hepatocyte Glycogen Contents, $\times 40$

trichloromethyl free radicals causing LP and producing hepato cellular damage $[20,21]$. The results of the present study indicated that serum level activity of ALT, AST and ALP in the groups $\mathrm{CCl}_{4}$ and $\mathrm{CCl}_{4}+\mathrm{AuNP}$ which received $\mathrm{CCl}_{4}$ in trial period significantly increased compared to control. In addition, Lactate dehydrogenase (LDH) value in group $\mathrm{CCl}_{4}+\mathrm{AuNP}$ significantly increased compared to $\mathrm{CCl}_{4}$ but did not show any significant differences compared to the control group. Moreover, the MDA rates in group $\mathrm{CCl}_{4}+\mathrm{AuNP}$ and $\mathrm{CCl}_{4}$ significantly decreased compared to the control group. Our findings revealed that blood superoxide dismutase (SOD), in group $\mathrm{CCl}_{4}+\mathrm{AuNP}$

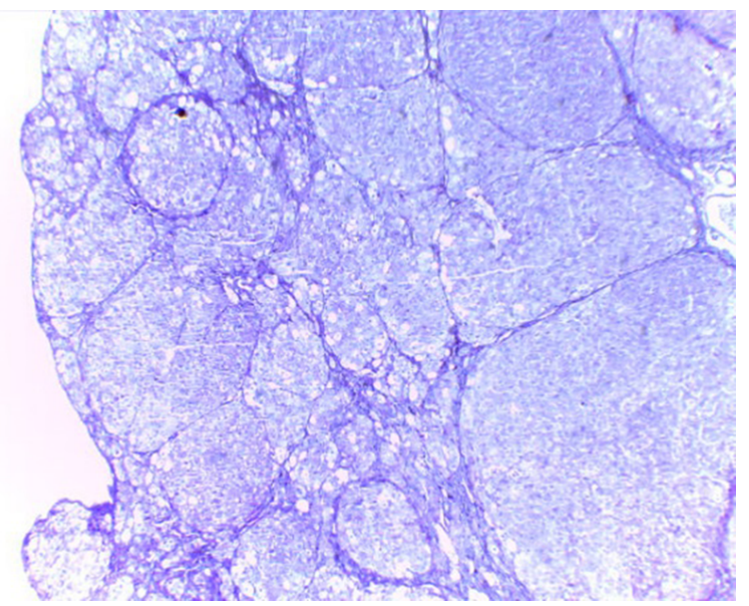

Figure 8. Low Power Micrograph of a PAS Stained Section of $\mathrm{CCL}_{4}$ and Nanoparticle Experimental Group with Micro Nodular Cirrhotic Changes and Prominent Reduction of Hepatocyte Glycogen Contents, $\times 4$

significantly increased compared to $\mathrm{CCl}_{4}$, but did not show any significant differences compared to the control group. The results in the present study showed that the serum liver enzymes activity (ALT, AST, and ALP) significantly increased in the groups which received $\mathrm{CCl}_{4}$. This section of the results is consistent with the findings by Ahmed A. Elberry, et al. (2010) who reported that $\mathrm{CCl}_{4}$ is an important toxin which prompts liver injury by elevating serum levels of liver enzymes such as ALT, AST, ALP (16) and also reported the severity of liver damage [16]. Our results revealed that AST, ALT and ALP in group $\mathrm{CCl}_{4}+\mathrm{AuNP}$ did not show any significant differences with those of group $\mathrm{CCL}_{4}$ and are then in in line with the findings by Clinton Rambanapasi, et al. (2016) who reported that the indicators of liver damage, AST and ALT showed no significant differences between the control and experimental groups [18]. The results in the present study were promised by Shu Dong, et al. (2016) who reported that toxicological mechanisms of $\mathrm{CCl}_{4}$-induced liver fibrosis may be related to multi biological manner mechanisms for $\mathrm{CCl}_{4}$ detoxication in the liver [5]. Poli G, (2000) reported that fibrotic process in the liver, which is induced by chemical mediators, promotes expression and synthesis of inflammatory and pro-fibrogenic cytokine and lipid peroxidation products [21]. In addition, our results showed that MDA values in group $\mathrm{CCl}_{4}$ and $\mathrm{CCl}_{4}+\mathrm{AuNP}$ significantly decreased compared to the control group and are consistent with the findings by Poli G (2000) who reported that chemical mediators stimulate lipid peroxidation products [21].

Our results also showed that pathological changes due to $\mathrm{CCl}_{4}$ injection, including fatty metamorphosis, cirrhotic changes and vascular congestion and dilatation are part 
of complex toxic effects of this organic compound which had a little hepatic protective effect on morphology and function of liver cells. Barathmanikanth S. et al. (2010) found out that gold nanoparticles inhibit the ROS generation at hyperglycemic conditions; scavenging free radicals and preventing oxidative stress in streptozotocin induced diabetic mice [22]. Our findings in the current study, furthermore, revealed that superoxide dismutase (SOD) in group $\mathrm{CCl}_{4}+$ AuNP significantly increased compared to $\mathrm{CCl}_{4}$ which was in agreement with those of Siddiqi NJ. (2014) who demonstrated that gold nanoparticles administration in animals changed the expression pattern of SOD activity in various tissues. For example, maximum SOD activity was detected in liver and minimum in spleen [10]. Besides, Abdelhalim MA, et al. (2015) reported that administration of $10 \mathrm{~nm}$ AuNP for exposure duration of 3 and 7 days in rats caused a significant decrease in SOD levels in specimens of liver [23] compared to that of control which is inconsistent with our findings. These differences may be due to animals' model and size of gold nanoparticle.

\subsection{Conclusion}

Our findings in the present study revealed that AuNP administration in liver toxicity induced by $\mathrm{CCl}_{4}$ in male rats affected blood SOD and MDA values but did not show any changes in serum liver enzymes activity. In addition, AuNP did not show any protective effects against induced fatty metamorphosis and cirrhotic changes in experimental group.

\section{Acknowledgments}

This study was financially supported by the deputy research center at Zahedan University of Medical Sciences (project No: 7355). We are grateful to Dr Ali Reza Nakhei for his kind cooperation.

\section{Footnotes}

Authors' Contribution: Mohammad Reza Shahraki, Hamideh Mirshekari and Mohammad Reza Arab developed the original idea, protocol and wrote the manuscript. Fereshteh Badini collected the data and other authors, analyzed the data.

Conflict of Interests: The authors declare no conflict of interest.

Funding/Support: Zahedan University of Medical Sciences.

\section{References}

1. Demirdag K, Bahcecioglu IH, Ozercan IH, Ozden M, Yilmaz S, Kalkan A. Role of L-carnitine in the prevention of acute liver damage induced by carbon tetrachloride in rats. J Gastroenterol Hepatol. 2004;19(3):333-8. doi: 10.1111/j.1440-1746.2003.03291.x. [PubMed: 14748882].

2. Poon KL, Wang X, Ng AS, Goh WH, McGinnis C, Fowler S, et al. Humanizing the zebrafish liver shifts drug metabolic profiles and improves pharmacokinetics of CYP3A4 substrates. Arch Toxicol. 2017;91(3):118797. doi: 10.1007/s00204-016-1789-5. [PubMed: 27485346].

3. Cagen SZ, Klaasen CD. Carbon tetrachloride-induced hepatotoxicity: studies in developing rats and protection by zinc. Fed Proc. 1980;39(13):3124-8. [PubMed: 7428956].

4. Simeonova PP, Gallucci RM, Hulderman T, Wilson R, Kommineni C, Rao M, et al. The role of tumor necrosis factor-alpha in liver toxicity, inflammation, and fibrosis induced by carbon tetrachloride. Toxicol Appl Pharmacol. 2001;177(2):112-20. doi: 10.1006/taap.2001.9304. [PubMed: 11740910].

5. Dong S, Chen QL, Song YN, Sun Y, Wei B, Li XY, et al. Mechanisms of $\mathrm{CCl} 4$-induced liver fibrosis with combined transcriptomic and proteomic analysis. J Toxicol Sci. 2016;41(4):561-72. doi: 10.2131/jts.41.561. [PubMed: 27452039].

6. Mhashal AR, Roy S. Effect of gold nanoparticle on structure and fluidity of lipid membrane. PLoS One. 2014;9(12):e114152. doi: 10.1371/journal.pone.0114152. [PubMed: 25469786].

7. Binder WH, Sachsenhofer R, Farnik D, Blaas D. Guiding the location of nanoparticles into vesicular structures: a morphological study. Phys Chem Chem Phys. 2007;9(48):6435-41. doi: 10.1039/b711470m. [PubMed: 18060174].

8. Tu Y, Lv M, Xiu P, Huynh T, Zhang M, Castelli M, et al. Destructive extraction of phospholipids from Escherichia coli membranes by graphene nanosheets. Nat Nanotechnol. 2013;8(8):594-601. doi: 10.1038/nnano.2013.125. [PubMed: 23832191].

9. Ghosh P, Han G, De M, Kim CK, Rotello VM. Gold nanoparticles in delivery applications. Adv Drug Deliv Rev. 2008;60(11):1307-15. doi: 10.1016/j.addr.2008.03.016. [PubMed: 18555555].

10. Siddiqi NJ. Effect of gold nanoparticles on superoxide dismutase and indoleamine 2, 3-dioxygenase in various rat tissues. Indian J Biochem Biophys. 2014;51(2):156-9. [PubMed: 24980020].

11. Connor EE, Mwamuka J, Gole A, Murphy CJ, Wyatt MD. Gold nanoparticles are taken up by human cells but do not cause acute cytotoxicity. Small. 2005;1(3):325-7. doi: 10.1002/smll.200400093. [PubMed: 17193451].

12. De Jong WH, Hagens WI, Krystek P, Burger MC, Sips AJ, Geertsma RE. Particle size-dependent organ distribution of gold nanoparticles after intravenous administration. Biomaterials. 2008;29(12):1912-9. doi: 10.1016/j.biomaterials.2007.12.037. [PubMed:18242692].

13. Sung JH, Ji JH, Park JD, Song MY, Song KS, Ryu HR, et al. Subchronic inhalation toxicity of gold nanoparticles. Part Fibre Toxicol. 2011;8:16. doi: 10.1186/1743-8977-8-16. [PubMed: 21569586].

14. Umair M, Javed I, Rehman M, Madni A, Javeed A, Ghafoor A, et al. Nanotoxicity of Inert Materials: The Case of Gold, Silver and Iron.J Pharm Pharm Sci. 2016;19(2):161-80. doi: 10.18433/J31021. [PubMed: 27518167].

15. Padmanabhan P, Kumar A, Kumar S, Chaudhary RK, Gulyas B. Nanoparticles in practice for molecular-imaging applications: An overview. Acta Biomater. 2016;41:1-16. doi:10.1016/j.actbio.2016.06.003. [PubMed: 27265153].

16. Elberry AA, Harraz FM, Ghareib SA, Nagy AA, Gabr SA, Suliaman MI, et al. Antihepatotoxic effect of marrubium vulgare and withania somnifera extracts on carbon tetrachloride-induced hepatotoxicity in rats. J Basic Clin Pharm. 2010;1(4):247-54. [PubMed: 24825994].

17. Bhandarkar MR, Khan A. Antihepatotoxic effect of Nymphaea stellata willd., against carbon tetrachloride-induced hepatic damage in albino rats. J Ethnopharmacol. 2004;91(1):61-4. doi: 10.1016/j.jep.2003.11.020. [PubMed: 15036469]. 
18. Rambanapasi C, Zeevaart JR, Buntting H, Bester C, Kotze D, Hayeshi R, et al. Bioaccumulation and Subchronic Toxicity of $14 \mathrm{~nm}$ Gold Nanoparticles in Rats. Molecules. 2016;21(6) doi: 10.3390/molecules21060763. [PubMed: 27294904].

19. Drotman RB, Lawhorn GT. Serum enzymes as indicators of chemically induced liver damage. Drug Chem Toxicol. 1978;1(2):163-71. doi: 10.3109/01480547809034433. [PubMed: 755666].

20. Tsukamoto H, Matsuoka M, French SW. Experimental models of hepatic fibrosis: a review. Semin Liver Dis. 1990;10(1):56-65. doi: 10.1055/s2008-1040457. [PubMed: 2110685].

21. Poli G. Pathogenesis of liver fibrosis: role of oxidative stress. Mol
Aspects Med. 2000;21(3):49-98. doi: 10.1016/S0098-2997(00)00004-2. [PubMed: 10978499].

22. Barathmanikanth S, Kalishwaralal K, Sriram M, Pandian SR, Youn HS, Eom S, et al. Anti-oxidant effect of gold nanoparticles restrains hyperglycemic conditions in diabetic mice. J Nanobiotechnology. 2010;8:16. doi: 10.1186/1477-3155-8-16. [PubMed: 20630072].

23. Abdelhalim MA, Al-Ayed MS, Moussa SA. The effects of intraperitoneal administration of gold nanoparticles size and exposure duration on oxidative and antioxidants levels in various rat organs. PakJPharm Sci. 2015;28(2 Suppl):705-12. [PubMed: 25796162]. 